\title{
ALGUNOS RASGOS DEL HABLA FEMENINA EN LA CISTELLARIA DE PLAUTO
}

\author{
Maricela Cerdas Fallas
}

\section{(c)}

Doi: https://doi.org/10.15517/rfl.v46iEspecial.41707

URL: https://revistas.ucr.ac.cr/index.php/filyling/index 



\title{
ALGUNOS RASGOS DEL HABLA FEMENINA EN LA CISTELLARIA DE PLAUTO
}

\author{
FEMALE SPEECH IN PLAUTUS' CISTELLARIA
}

Maricela Cerdas Fallas

\begin{abstract}
RESUMEN
En la Antigüedad grecolatina se observaban diferencias en la forma de hablar de hombres y mujeres. Este artículo examina los diversos mecanismos que caracterizan el habla de personajes femeninos en la comedia Cistellaria, de Tito Maccio Plauto, autor romano del siglo II a. C.. Entre ellos se cuentan algunos juramentos normalmente usados por mujeres y fórmulas de cortesía, consideradas como un rasgo típico del habla femenina.

Palabras clave: Plauto; comedia romana; sexolecto; habla femenina; pragmática.
\end{abstract}

\begin{abstract}
In the Graeco-Roman world there was an awareness of the existence of differences between male and female speech. This article describes the various mechanisms that characterize the speech of female characters in the comedy Cistellaria, by Roman author Titus Maccius Plautus (II BC). Some of them include swear words normally used by women and politeness strategies, considered typical of female speech.
\end{abstract}

Keywords: Plautus; Roman comedy; sexolect; female speech; pragmatics.

\section{Estudios pragmáticos en lengua latina}

La lengua latina, al no contar con hablantes nativos, ha recibido bastante menos atención que otras lenguas por parte de los estudiosos de la lingüística. Sin embargo, el latín posee gran importancia, pues es el antepasado de las lenguas romances, entre ellas la nuestra, el español. Además, es precisamente mediante el estudio del latín que se puede apreciar mejor el legado cultural que Roma dejó en Occidente.

M. L. Maricela Cerdas Fallas. Profesora de la Escuela de Filología, Lingüística y Literatura. Universidad de Costa Rica. Costa Rica. Correo electrónico: maricela.cerdas@ucr.ac.cr

Recepción: 20- 06- 19

Aceptación: 12-11- 19 
El problema al analizar la lengua latina es que, precisamente por no ser una lengua 'viva', no es posible obtener diálogos reales con las que llevar a cabo estudios de conversación. Para el análisis del discurso oral en latín se cuenta solamente con testimonios escritos: inscripciones parietales como grafitti y textos literarios que tratan de representar conversaciones coloquiales. Entre los textos literarios, aquellos que están dirigidos claramente hacia un receptor, tales como la oratoria, la epistolografía y el teatro, son los que se prestan mejor para estudios pragmáticos. Particularmente, el drama cómico, con sus diálogos y sus expresiones coloquiales, es el que ofrece una satisfactoria documentación de la lengua latina hablada. Por ello, parece la opción más aceptable para hacer análisis pragmáticos ${ }^{1}$. Hay que tener claro, sin embargo, que estos diálogos del teatro, al ser reproducidos por escrito y ser una creación literaria, son más pulidos que los espontáneos.

\section{Plauto y la Cistellaria}

Dentro del género dramático en la Roma antigua, la comedia palliata ${ }^{2}$, es decir, la comedia latina con temas y personajes inspirados en la comedia griega con el fin de evitar la censura de la sociedad romana, tiene especial importancia. Es aquí donde la figura de Tito Maccio Plauto (siglo II a. C.) destaca como el autor más representativo. Fue muy popular en su tiempo, tanto que incluso muchas obras de otros autores llevaban su nombre para garantizar una buena acogida (Marchesi, 1971, p. 48), lo que es muestra de que el comediógrafo lograba ampliamente la satisfacción del público. Su obra es muy original, a pesar de que, como ya se mencionó, los temas de la comedia palliata toman como modelo la comedia nueva griega.

Plauto es reconocido tanto por su manejo de la lengua latina, según Millares "[...] llena de enjundia y colorido, de efectos imprevistos y de juegos de palabras, muchas de su invención" (1995, p. 34), como por la fuerza cómica presente en sus obras. Este autor conocía a su público muy bien y sabía por eso qué elementos le ayudarían a lograr el propósito de la comedia: la risa.

La figura de Plauto no reviste importancia únicamente por su papel como comediógrafo; para la lengua latina arcaica, en palabras de Penney (2011, p. 222), “[...] the only complete texts to survive are the comedies of Plautus and Terence, and the language of these authors, especially Plautus, provides the fullest representation that we have of Old Latin at the close of the third century and in the first half of the second"3.

La Cistellaria está basada en la comedia original griega Synaristosai, de Menandro. A pesar de que le faltan algunos fragmentos, los cuales no afectan la comprensión de la trama, evidencia el estilo característico de Plauto para estructurar una obra: dos jóvenes, Alcesimarco y Selenia, quien trabaja como cortesana en la casa de una lena, están enamorados. Sin embargo, no pueden estar juntos, pues el padre de Alcesimarco lo prometió en matrimonio a la hija de Demifón, su vecino rico. Los involucrados ignoran el hecho de que Selenia es en realidad la hija de este vecino, y que había sido expuesta al nacer junto con una cestita que

$1 \quad$ Véase al respecto Núñez (1995, p. 348).

2 De pallium, el equivalente griego de la toga romana. Plauto (2016, Mil., vv. 685-689) hace una descripción de este manto.

3 " $3[. .$.$] los únicos textos completos que sobreviven son las comedias de Plauto y Terencio, y la lengua de$ estos autores, especialmente Plauto, ofrece la representación más completa que tenemos de latín arcaico de finales del siglo III a.C. y en la primera mitad del siglo II. a. C." (traducción propia). 
contenía sonajeros (cistella), de donde viene el título de la obra. Por su parte, Fanóstrata (esposa de Demifón), la madre de Selenia, la busca desesperadamente. El problema se soluciona con el reconocimiento de Selenia como joven de buena familia, lo que posibilita el final feliz: Alcesimarco y Selenia tienen permiso de casarse.

A continuación, se ofrece una lista de personajes que intervienen en la comedia, con el fin de facilitar la comprensión del análisis posterior:

Selenium - meretrix / cortesana

Gymnasium - meretrix / cortesana

Syra - lena, madre de Gimnasia

Dios Auxilio - encargado del prólogo

Alcesimarco - adulescens / joven enamorado de Selenia

Servus / esclavo de Alcesimarco

Senex / viejo, padre de Alcesimarco

Lampadión - servus / esclavo de Fanóstrata

Melénide - lena / madre adoptiva de Selenia

Fanóstrata - matrona / madre de Selenia

Halisca - ancilla / esclava de Melénide

Demifón - senex / viejo, vecino de Alcesimarco

\section{Sexolecto femenino y su percepción en la Antigua Roma}

Dentro del vasto campo de la lingüística, la sociolingüística es la rama que se ocupa de estudiar el lenguaje en relación con la sociedad en que encuentra su contexto. Factores como la edad, el sexo, la clase social o el tipo de educación recibida por los interlocutores han demostrado tener influencia sobre una lengua.

En el campo de la sociolingüística, una de las variables de análisis más importantes es la que depende del sexo o género del hablante; "su correlación con las distintas variantes lingüísticas resulta muy significativa, ya que, en principio, hombres y mujeres hablan de forma diferente" (Serrano, 2008, p. 176). Es más, en palabras de Calero, "la existencia de sexolectos es un universal lingüístico. Todas las comunidades de habla presentan, en mayor o menor medida, diferencias en el uso que mujeres y varones hacen del sistema de comunicación verbal y no verbal" (1999, p. 69). El uso singular que hacen las mujeres de la lengua se conoce como feminolecto.

La época antigua grecolatina no era la excepción, pues ya desde entonces existía una conciencia acerca de las diferencias entre los hombres y las mujeres a la hora de hablar. Por ejemplo, Cicerón en De oratore, enfatiza la predisposición femenina al uso arcaizante de la lengua:

\footnotetext{
En verdad que cuando oigo a mi suegra Lelia -las mujeres conservan más fácilmente la lengua de los antiguos sin cambios, pues al no participar en la conversación con mucha gente mantienen siempre lo que aprendieron de pequeñas-, digo, que tal la oigo que me parece estar oyendo a Plauto o a Nevio: su tono de voz resulta tan derecho y sencillo que no parece encerrar afectación o imitación alguna; y de ello colijo que así hablaba su padre, así sus antepasados; no con tosquedad, como aquel a quien antes me he referido, ni de forma deslavazada o rústica o entrecortada, sino de modo preciso, igual y agradable (2002, p. 392).
}

Otro elemento atribuido por los antiguos romanos al habla femenina es "[...] la idea de que existían particularidades femeninas de pronunciación, pues se dice [...] que las 
mujeres suelen tener una pronunciación afectada (cerrando la boca y recortando las palabras)" (Quintillà, 2005, p. 49), que ellas eran por naturaleza indiscretas y excesiva e innecesariamente locuaces y que se caracterizaban por su tendencia a retardar el discurso (tardiloquium) (pp. 50-51). Además, se consideraba mal visto en las mujeres el uso de lenguaje indecente (Gilleland, 1980, p. 182). También, como aún en la actualidad sucede, se pensaba que el discurso femenino era de carácter eminentemente emotivo, a veces quejumbroso y tendiente a la autocompasión.

En la comedia palliata, se ha reconocido como característica distintiva el hecho de que tanto Plauto como Terencio adaptaron la lengua de sus personajes según el tipo al que estos pertenecen ${ }^{4}$. Adams (1984, pp. 43-45) acota que, en la comedia plautina, el habla de personajes femeninos contiene elementos que la distinguen de la de los personajes masculinos, como uso de juramentos, diferencias de pronunciación y mayor frecuencia de empleo de fórmulas de cortesía.

\section{Mecanismos caracterizadores del habla femenina en lengua latina}

Es importante recalcar que, al referirse al habla femenina, no se trata por lo general de usos exclusivos de mujeres, sino más bien de tendencias predominantes entre hablantes femeninas 5 .

En la misma línea de Adams (1984), Quintillà (2005) precisa como rasgos característicos del habla femenina en la comedia romana los siguientes aspectos, ya observados por Adams:

a. Juramentos. Existen expresiones que son utilizadas por hombres (como hercle y su variante mehercle) y otros (como castor y mecastor) por mujeres.

b. Formas de cortesía. Son generalmente consideradas como un rasgo típico del habla femenina (Adams, 2005, p. 582). Se emplean con fines de atenuación, para mitigar un imperativo, una pregunta o una súplica. Quintillà encuadra en esta categoría las expresiones amabo, obsecro, quaeso y sis. Por su parte, Barrios-Lech (2016) incluye en esta lista la expresión noli + imperativo.

c. Interpelaciones afectivas. Consisten en el uso de nombres propios o apelativos (como mater, pater, leno, uxor, etc.) o el empleo de vocativo más mi / mea.

d. Términos enfáticos. Quintillà los define como "términos vacíos o casi vacíos de su significado léxico y usado esencialmente para expresar sentimiento, especialmente angustia y conmiseración" (2005, p. 60). En la comedia latina se trata por lo general del adjetivo miserla.

\section{Ejemplos de habla femenina en la Cistellaria}

\section{$5.1 \quad$ Juramentos}

En la Antigua Roma, era común el uso de juramentos. Principalmente se juraba por distintos dioses y ya existía la idea de que cada sexo utilizaba juramentos distintos. Aulo Gelio (2006, libro 11, sección 6) menciona que "en los documentos antiguos ni las mujeres romanas juran por Hércules, ni los hombres por Cástor. Está claro, no obstante, por qué ellas no juraban

$4 \quad$ Véanse de Melo (2012, p. 322) y Román Bravo (2010, p. 66).

$5 \quad$ Véase al respecto Adams (1984, p. 44). 
por Hércules, ya que no participan en los sacrificios en honor de Hércules". Esto se explica por cuanto las mujeres tenían prohibido participar en los cultos a Hércules realizados en el Ara Maxima. Según Macrobio y Propercio, cuando Hércules viajaba por los campos de Italia con el ganado de Gerión, sediento se acercó a una mujer y le pidió agua, mas esta se negó debido a que se estaba celebrando la fiesta de la Bona Dea (exclusiva para mujeres) y ningún hombre podía tomar nada de lo concerniente a esta fiesta. Ante esto, Hércules instituyó un ritual y excluyó a las mujeres de su participación.

Además, menciona Aulo Gelio que los hombres no utilizaban la expresión mecastor, mientras que "[...] edepol, fórmula de juramento por Pólux, es común a hombres y mujeres" (2006, libro 11, sección 6). Se establece así que el juramento por Hércules (hercle, mehercle) era exclusivamente masculino, mientras que las mujeres juraban por Cástor (mecastor) o por Pólux ( $p o l$, edepol). El último juramento puede ser usado por ambos sexos. Ante la existencia de esta división, Quintillà apunta que "[...] un juramento femenino en boca de un hombre es un recurso habitual en la comedia para destacar el carácter afeminado del hablante” (2005, p. 56).

\subsubsection{Castor, ecastor}

Cástor era el hijo del rey espartano Tíndaro y de Leda, amada por Zeus. Con su hermano gemelo Pólux (los llamados Dióscuros) servían como guía a los marineros y eran los patronos de los equites, la caballería romana. Clasificada como interjección (Lewis y Short, 1879) o adverbio, esta forma de juramento es usada particularmente por las mujeres. En la comedia analizada, se aprecian 8 apariciones de castor y 8 de ecastor: según Ernout y Meillet (2001, p. 190), sirven para apoyar una afirmación o una negación, como en los ejemplos que se presentan a continuación:

a. El servus Lampadión y la matrona Fanóstrata hablan sobre la esclava Halisca, a quien han estado espiando.

LAMP. Mala mers, era, haec et callida est.

Esta es mala mercancía, ama, y es astuta.

PHAN. Ecastor ita videtur.

Por Cástor que así parece 6 (v. 727).

b. La lena, madre de la meretriz Gymnasium, expresa alegría al ver que la muchacha obedece sus indicaciones.

LENA. Ecastor haud me paenitet, si ut dicis ita futura es.

Por Cástor que no me causa arrepentimiento, si como dices así serás (v. 47).

\subsubsection{Pol, edepol}

Pólux era el hermano de Cástor, como se mencionó. Clasificado como interjección (Lewis y Short, 1879), y usado como fórmula de juramento, en la Cistellaria aparece pol 7 veces y edepol 6; el primero es utilizado solamente por personajes femeninos. Igual que castor, pol se usa para apoyar una afirmación o una negación, o como fórmula enfática de expresión de emociones, como ilustran los siguientes pasajes:

$6 \quad$ El texto latino de la Cistellaria fue tomado de la edición de Plauto (1935) y de Delphi Classics (2016). Las traducciones al español son de la autora del artículo. 
a. La esclava Halisca tiene la esperanza de que el esclavo Lampadión le diga dónde está el sonajero, por lo que se exalta cuando oye las palabras de este y de ahí el uso de pol.

LAMP. Est quidam homo, qui illam ait se scire ubi sit.

Hay cierto hombre, quien dice que él sabe dónde está (el sonajero) (v. 735).

HAL. At pol ille a quadam muliere, si eam monstret, gratiam ineat.

Por Pólux que aquel si se la muestra se ganaría la gratitud de cierta mujer (v. 736).

b. En este pasaje, la cortesana Gymnasium, ante la orden de su madre de marcharse rápidamente, hace una referencia, cargada de picardía, a su oficio y enfatiza lo dicho con el uso de pol.

GYM. Pol ad cubituram, mater, magis sum exercita

Por Pólux que a estar echada, madre mía, más diestra soy

fere quam ad cursura $<\mathrm{m}>$ : eo sum tardiuscula.

generalmente que a correr de aquí para allá: en eso soy muy lentita (vv. 379-380).

c. En este ejemplo, la lena exhorta a Selenium a cultivar la solidaridad entre cortesanas. Para esto, utiliza pol como un enfatizador de su aseveración.

\author{
LENA. Decet pol, mea Selenium, \\ LENA. Por Pólux conviene, mi Selenium, \\ hunc esse ordinem benevolentis inter se \\ que esta clase social sea benévola entre sí [...] (vv. 22-23).
}

\title{
5.1.3 Hercle
}

Hércules, héroe de la fuerza y protector de las riquezas, era el hijo de Júpiter y Alcmena. Su nombre es la forma latinizada, tal vez por intermedio etrusco (Grimal, 1981, p. 260), del griego Heracles y su culto estaba extendido por el territorio romano. El vocablo hercle es la contracción de hercule, y existe también la variante mehercle. Clasificado como interjección (Lewis y Short, 1879) y como adverbio, se usa como forma de juramento y, según Lewis, como aseveración.

Es importante mencionar el hecho de que, aunque hercle se considera desde la Antigüedad un juramento típicamente masculino, en la Cistellaria ocurre una instancia en que este vocablo es utilizado por un personaje femenino en las comedias de Plauto:

GYMN. Equidem hercle addam operam sedulo; sed tu aufer istaec verba, Por Hércules que en verdad yo aumente con esmero mis esfuerzos; pero tú deja esas palabras, meus oculus, mea Selenium [...] mi ojito, mi Selenium [...] (vv. 52-53).

De acuerdo con Dutsch (2008, p. 7), esta utilización femenina de un juramento masculino se puede interpretar como una muestra de asertividad del personaje, en este caso, la cortesana Gymnasium, quien se comporta de manera firme y decidida, en contraste con la joven Selenium, de carácter más dócil.

\subsection{Formas de cortesía}

Se tratan de marcadores pragmáticos, que, según Molinelli (2013, p. 3), tienen una motivación deíctica; en este caso, "[...] to modulate the illocutionary form of the utterance 
(e.g. mitigation) or indicate politeness strategies"7. En esta categoría, se incluyen los vocablos amabo, obsecro, quaeso y sis, los cuales poseen varios aspectos en común: proceden originalmente de formas verbales, son expresiones utilizadas en la comedia plautina como medio de atenuar un imperativo o una pregunta (Quintillà, 2005, p. 58) y son empleados en situaciones en que están de por medio intensas emociones.

\subsubsection{Amabo: te ruego, por favor}

Esta expresión es una forma verbal en tiempo futuro simple del verbo 'amare', usada como adverbio e igualmente como interjección de cariño y amistad (Blánquez, 1985, p. 133). Puede encontrarse tanto en posición inicial como parentética y final y aparece en 9 ocasiones. En la comedia plautina analizada, solo los personajes femeninos hacen uso de este marcador: Selenium, Halisca, Fanóstrata y Gymnasium. Esta forma presenta distintos usos que se enumeran a continuación:

a. En preguntas directas, como una forma de mostrar cortesía, como medio para atenuar la pregunta.

HAL. Ecquem vidisti quaerere hic, amabo, in hac regione ¿Acaso has visto a alguien buscar aquí, por favor, en esta zona cistellam cum crepundiis, quam ego hic amisi misera?

una cestita con sonajeros, la que yo miserable aquí perdí? (vv. 708-709).

Aquí, la esclava Halisca hace su pregunta a la uxor Fanóstrata, por lo que recurre a la cortesía para dirigirse a ella. Además, está desesperada y ansiosa por encontrar la canastita que por descuido perdió y que constituye la clave para el reconocimiento de Selenium. Por ello, en su interrogación se evidencia lo mucho que está en juego para ella.

PHAN. An, amabo, meretrix illa est quae illam sustulit? ¿Acaso, por favor, es meretriz aquella que la recogió? (v. 564).

En este caso se trata de la uxor Fanóstrata, quien hace esta pregunta con el anhelo de encontrar a su hija expuesta, por lo que desea que su pesquisa sea bien recibida.

b. En situaciones en que se realiza un ruego o una súplica, igualmente como recurso de atenuación.

SEL. Facis bene et amice. Sed tu, Gymnasium mea,

Lo haces amable y afablemente. Mas tú, mi Gymnasium

si me absente Alcesimarchus veniet, nolito acriter

si en mi ausencia Alcesimarco viene, no quiero que le grites

eum inclamare (utut erga me est meritus, mihi cordi est tamen),

cruelmente (cualquiera que haya sido su conducta conmigo, sin embargo le tengo cariño)

sed, amabo, tranquille: ne quid, quod illi doleat, dixeris.

pero, te ruego, quédate tranquila: no dirás nada que a él le cause dolor (vv. 107-110).

7 "[...] modular la forma elocutiva del enunciado (es decir, mitigación) o indicar estrategias de cortesía" (traducción propia). 
La puella Selenium aquí hace un ruego a su querida amiga la meretriz Gymnasium, para que no trate mal a su amado Alcesimarco. Selenium teme esto, pues es consciente del afecto de su amiga y le inquieta que insulte o expulse a Alcesimarco, causante de su sufrimiento.

SEL. Amabo, accurrite ne se interemat.

Por favor, acudid corriendo para que no se quite la vida (vv. 643-644).

Aquí, Selenium hace una petición encarecida de ayuda para evitar que su amado Alcesimarco, en su desesperación por no poder estar con ella, se suicide.

c. En estos versos, se puede observar el uso de amabo como expresión de cariño de la meretriz Gymnasium hacia su amiga Selenuim.

GYMN. Cura te, amabo.

GYMN. Pero cuídate, te ruego (v. 113).

Como se puede observar en los ejemplos anteriores, amabo se emplea en momentos emotivos para los personajes.

\subsubsection{Obsecro}

Obsecro es una forma verbal en tiempo presente indicativo del verbo 'obsecrare', usada como fórmula en las conversaciones (Blánquez, 1985, p. 1047). De acuerdo con Campos (2011, p. 29), "[...] obsecro es un verbo compuesto por la preposición $o b$ (por causa de) y el adjetivo sacer (sagrado). En su etimología, expresa una apelación a lo sagrado. Aunque, como fórmula de cortesía significa 'por favor', en realidad equivaldría, siempre en un contexto semejante, a 'por Dios, se lo suplico', de manera enfática”. Este vocablo es utilizado 16 veces en la obra; al igual que con amabo, este marcador se usa en diversas instancias:

a. En preguntas directas, donde igualmente ejerce una función de atenuación.

GYMN. Equidem hercle addam operam sedulo; sed tu aufer istaec verba,

Por Hércules que en verdad yo aumente con esmero mis esfuerzos; pero tú deja esas palabras, meus oculus, mea Selenium, numquam ego te tristiorem

mi ojito, mi Selenium, nunca más triste

vidi esse; quid, cedo, obsecro tam abhorret hilaritudo?

te vi; por qué, dime, te pido, tanto se aparta la alegría? (vv. 53-54).

La meretriz Gymnasium hace esta pregunta con preocupación al ver a su amiga triste, y quiere incitar las confidencias, por lo que utiliza obsecro para no parecer demasiado inquisitiva.

b. En peticiones, donde acompaña expresiones de cariño y emociones.

PHAN. Servate di med, obsecro.

Oh, dioses, salvadme, os ruego (v. 573).

En el ejemplo anterior, la matrona Fanóstrata está escuchando al esclavo Lampadión relatar qué hizo con la niña que se le dio para exponer, quien es su hija. Está a punto de averiguar el paradero de la muchacha, por ello, suelta esta súplica llena de esperanza y a la vez temor. 


\subsubsection{Quaeso}

Esta expresión es una forma arcaica de quaero, en primera persona singular del tiempo presente de indicativo. En palabras de Campos (2011, p. 28), “[...] es un verbo transitivo, el cual, al igual que otros verbos, experimenta una modificación al emplearse en su forma intransitiva, momento en el que significa 'le ruego' y 'por favor". Aparece en la comedia plautina en posición parentética. Según Campos (2011, p. 28), "el uso de comas para separar quaeso indica que la expresión es un modificador oracional, propio de "por favor".

Su uso como forma de atenuación aparece en tres casos: dos en boca de personajes femeninos y una en boca de un esclavo.

a. En el primer caso, es la matrona Fanóstrata, la madre de la niña expuesta, quien recurre a este vocablo. Es evidente su extrema ansiedad por escuchar el final de la historia que relata Melénide y confirmar, por fin, el paradero de su hija, pero a la vez no quiere ser la causa de la interrupción del relato ni quiere ofender a quien habla, por lo que el uso de quaeso le permite apresurar a Melénide de manera cortés. Nótese también el uso de age, la forma de imperativo presente de segunda persona singular del verbo agere. Esta partícula transmite una exhortación al interlocutor, con el fin de incitarlo a actuar según desea el hablante. Dado que esta acción se puede percibir como descortés, el empleo de quaeso cumple su función de atenuación.

MEL. Iam horret corpus, cor salit.

Ya mi cuerpo se eriza, mi corazón salta.

Nam mihi ab hippodromo memini adferri parvolam

Pues recuerdo que a mí del hipódromo me llevaron a la pequeñita

puellam eamque me mihi supponere.

niña y la hice pasar por mía.

PHAN. Age perge, quaeso; animus audire expetit, Vamos, prosigue, por favor; mi alma anhela escuchar,

ut gesta res sit.

cómo sucedió el asunto (vv. 551-555).

b. En este ejemplo, igualmente se encuentra quaeso en boca de Fanóstrata, quien de nuevo arde en ansias de escuchar noticias de su hijita, en conversación con la esclava Halisca. El uso de quaeso le permite apremiar de manera cortés a su interlocutora.

PHAN. Hariolare.

Eres adivina.

Sed quaeso, ambages, mulier, mitte atque hoc age:

Pero por favor, mujer, deja los rodeos y haz esto:

eloquere, unde haec sunt tibi cito crepundia.

explica pronto de dónde has sacado este sonajero (vv. 747-749).

\subsubsection{Sis}

Se trata de la contracción de si vis, combinación formulaica de la conjunción si y la segunda persona singular presente indicativo del verbo volo. De acuerdo con Dickey (2006, p. 21), esta forma es frecuente en la comedia romana, donde se traduce normalmente 
como 'por favor'. También puede funcionar como medio para atenuar un imperativo, como se observa en el siguiente ejemplo, el único de la comedia y precisamente en boca de un personaje femenino:

GYMN. Equidem hercle addam operam sedulo; sed tu aufer istaec verba,

Por Hércules que en verdad yo aumente con esmero mis esfuerzos; pero tú deja esas palabras, meus oculus, mea Selenium, numquam ego te tristiorem mi ojito, mi Selenium, nunca más triste

vidi esse; quid, cedo, te obsecro tam abhorret hilaritudo?

te vi; por qué, dime, te pido, tanto se aparta la alegría?

Neque munda adaeque es, ut soles (hoc sis vide, ut petivit

No estás tan graciosalelegante como sueles (mira esto, por favor, como

suspiritum alte) et pallida es. Eloquere utrumque nobis,

lanzó un suspiro profundamente) y estás pálida. Dinos dos cosas,

et quid tibi est et quid velis nostram operam, ut nos sciamus.

qué te pasa y qué quieres de nuestra ayuda, para que sepamos (vv. 52-57).

\subsubsection{Noli + infinitivo}

Barrios-Lech afirma que la fórmula para expresar prohibición noli + infinitivo presenta un valor de cortesía:

The basis for this evaluation is the meaning of noli itself (do not want); to tell someone noli facere is more polite than to tell him or her ne fac because in the former case, the addressee is only told to lay aside her willingness to do something, she is not told to stop doing it tout court (Barrios-Lech, 2016, p. 18) ${ }^{8}$.

El mismo autor menciona que su uso se da en situaciones de ruego o solicitud, como forma de mitigación.

En la comedia analizada, se presenta esta estructura solamente dos veces, ambas en boca de personajes femeninos.

SEL. Facis bene et amice. Sed tu, Gymnasium mea,

Lo haces amable y afablemente. Mas tú, mi Gymnasium

si me absente Alcesimarchus veniet, nolito acriter

si en mi ausencia Alcesimarco viene, no quiero que le grites

eum inclamare (utut erga me est meritus, mihi cordi est tamen),

cruelmente (cualquiera haya sido su conducta conmigo, sin embargo le tengo cariño)

sed, amabo, tranquille: ne quid, quod illi doleat, dixeris.

pero, te ruego, quédate tranquila: no dirás nada que a él le cause dolor (vv. 108-110).

En el ejemplo anterior, es Selenium quien se dirige a su amiga Gymnasium con una súplica sobre un asunto sumamente importante para ella: su amado Alcesimarco. En este pasaje, Selenium está preocupada de que, por el afecto que le tienen a ella, ya sea su madre o Gymnasium

$8 \quad$ La base para esta evaluación es el significado de noli en sí mismo (no quieras); decirle a alguien no quieras hacerlo es más cortés que decirle no lo hagas porque en el primer caso, se le pide al interlocutor solamente dejar a un lado su voluntad de hacer algo, no se le ordena simplemente dejar de hacerlo (traducción propia). 
maltraten a quien ella ama, el adulescens. Por eso se justifica el uso de noli + infinitivo, e incluso más arriba en el mismo pasaje de la comedia se halla otra petición atenuada con amabo.

\subsection{Interpelaciones afectivas}

Como ya se indicó, consisten en el uso de nombres propios o apelativos (como mater, pater, leno, uxor, etc.) o el empleo de vocativo más mi / mea. Estas expresiones, por su contenido emotivo, son asociadas al discurso femenino: Gilleland (1980, p. 181) menciona que, según Elio Donato en su comentario a la obra de Terencio, el vocativo del posesivo meus se presta mejor para el discurso femenino.

Como ejemplo del uso de un apelativo cariñoso, tenemos el siguiente fragmento en boca de la meretrix Gymnasium:

GYMN. Necesse est, quo tu me modo voles esse, ita esse, mater.

Es necesario, que como tú quieres que yo sea, así sea, madre (v. 44).

Igualmente, lo encontramos en boca de la matrona Fanóstrata para dirigirse a la esclava Halisca.

PHAN. Mulier, mane. Sunt qui volunt te conventam.

Mujer, quédate. Hay quienes quieren hablarte (v. 703).

Por su parte, en la Cistellaria, el uso del posesivo mi / mea en vocativo predomina en el habla de los personajes femeninos. Se da en situaciones en que cada una de estas mujeres se dirige a otra mujer, por quien siente gran afecto: su compañera meretriz, su madre, etcétera.

a. En este ejemplo, tenemos a la puella Selenium dirigiéndose a su querida compañera, la meretrix Gymnaisum, con esta interpelación afectiva:

SELENIUM. Cum ego antehac te amavi et mi amicam esse crevi, Aunque antes de ahora te amé y te creí mi amiga a ti,

mea Gymnasium, et matrem tuam [...]

mi Gymnasium, y a tu madre [...] (v. 1-2).

b. En el siguiente fragmento, es más bien la lena, madre adoptiva de Selenium, quien habla afectuosamente con su hija:

LENA. Matronae magis conducibilest istuc, mea Selenium,

Para una matrona es más conveniente esto, mi Selenium,

unum amare et cum eo aetatem exigere quoi nuptast semel.

amar a uno solo y acabar la vida con aquel con quien te casaste una vez (v. 78-79).

c. Es interesante el caso de Halisca, la ancilla de Melénide, la lena que adoptó a Selenium. Ella fue quien perdió la cestita con los sonajeros que permitirá el reconocimiento de Selenium como ciudadana y su matrimonio con Alcesimarco. Al verse en tal embrollo, Halisca recurre a estas estructuras, para tratar de congraciarse con quienes podrían ayudarle. En primer lugar, se dirige a los espectadores, rompe la cuarta pared para involucrarlos en la acción y con estas expresiones busca lograr la captatio benevolentiae que necesita para salir de su apuro. Por supuesto, esta actuación contribuye también a la vis comica de la escena, pues representa el recurso cómico de la esclava torpe que busca lo que por su descuido perdió. 
HAL. Mi homines, mi spectatores, facite indicium, siquis vidit, Queridas personas, queridos espectadores, haced la denuncia, si alguien la vio, [si]quis eam abstulerit, quisve sustulerit, et utrum hac an illac iter institerit. si alguien se la llevó, o bien la hizo desaparecer, y si por aquí o por allá siguió el camino (vv. 678-679).

Luego se encuentra con Lampadión, el esclavo que, sin ella saberlo, recogió la canastita, y con Fanóstrata, la verdadera madre de Selenium. Ellos la interrogan acerca de sus actividades y ella, viendo una posibilidad ya sea de recibir ayuda o más bien de ser descubierta y castigada, se dirige a ellos usando estas estructuras, que buscan de igual manera congraciarse con sus interlocutores.

HAL. Mi homo et mea mulier, vos saluto.

Querido hombre y querida mujer, os saludo.

LAMP. Quid quaeritas?

¿Qué buscas? (vv. 723-724).

HAL. Cistellula mi hinc, adulescens, evolavit.

Una cestita a mí de aquí, querido joven, se me voló (v. 732).

HAL. Mi homo, obsecro, alias res geris: ego tibi meas res mando.

Querido hombre, te pido, tú estás en otras cosas: yo te encargo de mis asuntos (v. 719).

En la comedia analizada, solamente una vez un personaje masculino hace uso de estas expresiones, y es precisamente el adulescens Alcesimarco, en una escena en la que interviene su amada Selenia y la madre adoptiva de esta, Melénide. El joven está tratando de que Selenium lo perdone y echa mano de esta expresión, que es considerada emotiva, para demostrarle su amor y lograr que la joven se identifique con los sentimientos que él experimenta.

ALC. Mea<e i ssula sua 〈aede〉s egent. Ad me 〈sine ducam〉.

Mi mansión tiene necesidad de su dueña. A mi casa deja que (te) conduzca.

SEL. Aufer manum.

Quita la mano.

ALC. Germana mea sororcula.

Hermana mía, hermanita.

SEL. Repudio te fraterculum.

Te rechazo como hermanito.

ALC. Tum tu igitur, mea matercula.

Entonces tú por consiguiente, mi madrecita.

MEL. Repudio te puerculum.

Te rechazo como hijito.

ALC. Opsecro te...

Te pido...

SEL. Valeas.

Adiós (vv. 450-457). 


\title{
5.4 Términos enfáticos
}

En esta categoría, se encuentra el adjetivo miser/a, utilizado para expresar sentimientos de angustia. En Cistellaria lo utiliza Alcesimarco, el joven enamorado, quien con este vocablo externa su dolor por estar separado de la mujer que ama.

ALC. Iactor, crucior, agitor stimulor, versor

Soy arrojado, atormentado, perseguido, aguijoneado, agitado

in amoris rota, miser exanimor [...]

en la rueda del amor, desgraciado estoy agotado [...] (vv. 206-207).

Pero la mayor cantidad de apariciones de este adjetivo enfático se registra en boca de personajes femeninos: la joven Selenium, la lena Melénide y la esclava Halisca. En el caso de Selenium, ella sufre amargamente porque su amado está siendo obligado a casarse con otra, lo que la lleva a lamentarse y describirse a sí misma como misera.

SEL. Spissum istuc amanti est verbum, veniet, nisi venit.

Lenta es esta palabra para el amante, vendrá si no viene.

Sed ego mea culpa et stultitia peius misera maceror,

Pero desgraciada yo, por mi culpa y estupidez me atormentan (cada vez peor), quom ego illum unum mi exoptavi, quicum aetatem degerem.

porque yo a ese único para mí lo escogí, para pasar la vida con él (vv. 75-77).

En el siguiente ejemplo, tenemos una escena típica de la comedia plautina: el joven Alcesimarco, al verse separado de su amada, amenaza con suicidarse. Ante esto, Selenium expresa su angustia y temor con el vocablo misera.

\author{
SEL. Mater mea, \\ Madre mía, \\ periimus miserae. \\ nosotras desgraciadas estamos perdidas (vv. 640-641).
}

Para la lena Melénide la situación es igualmente angustiosa: su hija adoptiva Selenium está cerca de ser reconocida por su verdadera madre y, por consiguiente, separada de ella. Enfatiza sus sentimientos de temor con el uso de misera.

MEL.Sed quis hic est qui recta platea cursum huc contendit suom? ¿Pero quién es esta que en esta plaza hacia aquí se dirige en carrera?

Et illud paveo et hoc formido; ita tota sum misera in metu.

Por una parte aquello temo y por otra de esto tengo miedo; así estoy toda desgraciada en el miedo (vv. 534-535).

Finalmente, la esclava Halisca, quien se encuentra en un verdadero aprieto, pues extravió la canastita que debía servir para el reconocimiento de Selenuim, utiliza repetidamente misera como descripción de su estado emocional. Los siguientes ejemplos ilustran la angustiosa situación de esta mujer.

HAL. Nisi quid mi opis di dant, disperii, neque unde auxilium expetam habeo; Si los dioses no me dan algo de fuerza, estoy perdida, y no tengo de dónde esperar ayuda. itaque petulantia mea me animi miseram habet

$y$ de esta manera mi atolondramiento me tiene infeliz de ánimo quae in tergum meum ne veniant male formido, 
temo que vaya a parar a mi espalda lo malo, si era mea $<$ me $>$ sciat tam socordem esse quam sum. si mi ama sabe que soy tan descuidada como (en realidad) soy (vv. 671-673).

HAL: Ecquem vidisti quaerere hic, amabo, in hac regione ¿Acaso has visto a alguien buscar aquí, por favor, en esta zona cistellam cum crepundiis, quam ego hic amisi misera? una cestita con sonajeros, la que yo desgraciada aquí perdí? (vv. 708-709).

HAL. Disperii misera: quid ego erae dicam? Yo desgraciada estoy perdida: ¿qué le diré yo a mi ama? (v. 713).

\section{Conclusiones}

La sociolingüística parte del principio de que la lengua cambia según factores de tipo geográfico, cultural y contextual que caracterizan al hablante. Tal como sucede con las lenguas modernas, los estudios sociolingüísticos en latín cumplen uno de los principales propósitos de esta disciplina: relacionar al hablante con su lengua y con su medio. En el caso estudiado, el análisis de la comedia plautina Cistellaria ayuda a comprender cómo el habla de las mujeres romanas, representadas por los personajes femeninos, se diferencia efectivamente del habla masculina, a partir de la utilización de diversos mecanismos de atenuación, cortesía y expresión de afecto.

En primera instancia, con respecto a los juramentos, se observa un amplio empleo de estos vocablos a lo largo de la comedia. Se mantiene la norma, reconocida ya desde la Antigüedad, del uso de hercle por personajes masculinos y ecastor por femeninos. Además, pol es utilizado solo por personajes femeninos, mientras que edepol es usado dos veces por hombres y 4 por mujeres. Se da en la Cistellaria el caso del juramento hercle en boca de un personaje femenino, lo cual puede explicarse como un recurso del autor para representar el carácter más firme y asertivo de este personaje, la meretrix Gymnasium, en contraste con la puella Selenium, más dócil y obediente.

Las expresiones usadas como medio de cortesía son también de uso frecuente en la Cistellaria; de ellas, obsecro es el vocablo utilizado con mayor frecuencia. Estas expresiones se registran en la comedia predominantemente en boca de personajes femeninos y funcionan como vehículos de expresión del cariño entre personajes y como medio de atenuación ante preguntas directas. La Figura 1 ilustra el uso de estos marcadores según el sexo del hablante.

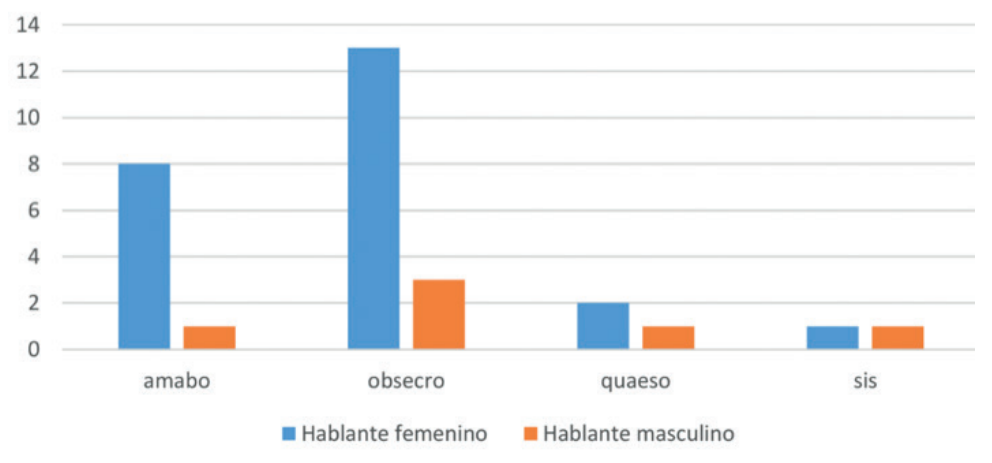

Figura 1. Frecuencia de aparición de expresiones de atenuación por género 
En el caso de las interpelaciones afectivas, su uso por parte de personajes femeninos de la misma categoría social (hermanas, madre e hija) funciona igualmente como vehículo de la expresión de cariño. Asimismo, su empleo por una esclava hacia quienes ella percibe, ya sea como una amenaza o como una oportunidad de recibir ayuda (la uxor Fanóstrata, el servus Lampadión), tiene más bien una función de cortesía.

Con relación al término enfático miser/misera, aunque no se pueda restringir su uso a los personajes femeninos, sí se aprecia un predominio de aparición en boca de mujeres. La instancia en que miser es usado por el adulescens Alcesimarco se puede explicar por cuanto este es, por lo general, el más emotivo de los personajes masculinos de la palliata y, en el caso específico de la Cistellaria, es el típico joven enamorado que ve su relación con su amada en peligro y se entrega a la desesperación.

Para concluir, es importante tener en consideración, al estudiar rasgos de habla femenina en una lengua como el latín, sin hablantes nativos, la observación de Adams: "In Latin most of the evidence for female speech comes from the pen of men writing female parts in drama; it is likely that to some extent they composed their speeches according to popular stereotypes of female behavior rather than from objective observations"9 (1984, p. 44).

\section{Bibliografía}

Adams, J. N. (1984). Female speech in Latin comedy. Antichthon, 8, 43-77. Recuperado de https://es.scribd.com/document/430437227/Adams-1984-Female-Speech-in-LatinComedy

Adams, J. N. (2005). Neglected Evidence for Female Speech in Latin. The Classical Quarterly, New Series, 55(2), 582-596.

Barrios-Lech, P. (2016). Noli + Infinitive in Roman Comedy. Glotta; Zeitschrift für Griechische und Lateinische Sprache, 92, 18-23.

Blánquez Fraile, A. (1985). Diccionario Latino-Español, Español-Latino. Barcelona: Editorial Ramón Sopena.

Calero, M. A. (1999). Sexismo lingüístico: análisis y propuestas ante la discriminación sexual en el lenguaje. Madrid: Narcea.

Campos Vargas, H. (2011). Cómo pedir un favor en latín: un estudio con base en la comedia plautina de La Olla (Aulularia). Káñina, 35(2), 27-35.

Cicerón. (2002). Sobre el orador. Madrid: Gredos.

de Melo, W. (2012). The Language of Roman Comedy. En Clackson, James (Ed.), A Companion to the Latin Language (pp. 321-343). Blackwell Publishing Ltd.

Dickey, E. (2006). The use of latin 'sis' as a focus marking clitic particle. Linguistics, Philology and Phonetics, 11, 21-25.

$9 \quad$ "En latín, la mayor parte de la evidencia de habla femenina viene de la pluma de hombres que escriben palabras femeninas en el drama; es posible que hasta cierto punto hayan compuesto sus discursos de acuerdo con estereotipos populares de comportamiento femenino más que a partir de observaciones objetivas" (traducción propia). 
Dutsch, D. M. (2008). Feminine Discourse in Roman Comedy: On Echoes and Voices. Oxford Studies in Classical Literature and Gender Theory. Recuperado de https://books. google.co.cr/books?id=KOep0QQ0ncUC\&printsec= frontcover\&source=gbs_ge_sum mary_r\&cad $=0 \# \mathrm{v}=$ onepage $\& \mathrm{q} \& \mathrm{f}=$ false

Ernout, A. y Meillet, A. (2001). Dictionnaire Étymologique de la langue latine: Histoire des mots. Klincksieck, Paris.

Gelio, A. (2006). Noches Áticas. León: Universidad de León, Secretariado de Publicaciones.

Gilleland, M. E. (1980). Female Speech in Greek and Latin. The American Journal of Philology, 101(2), 180-183.

Grimal, P. (1981). Diccionario de mitología griega y romana. Barcelona: Ediciones Paidós Ibérica.

Lewis, C. T. y Short, C. (1879). A Latin Dictionary. Founded on Andrews' edition of Freud's Latin dictionary. Oxford: Clarendon Press. [Versión digital]. Recuperado de http:// www.perseus.tufts.edu/hopper/text?doc=Perseus\%3atext\%3a1999.04.0059

Marchesi, C. (1971). Storia della letteratura latina. (Vol. I). Milán: Principato Editore.

Millares, C. (1995). Historia de la literatura latina. México, D. F.: Fondo de Cultura Económica.

Molinelli, P. (2013). Verb-based Functional Markers in Latin: Morphosyntax, Semantics, and Pragmatics at a Crossroad. Recuperado de http://www.mediling.eu/allegati/PRIN_t_ risorse/80/FILE_Documento_LCLMolinellirev.pdf

Núñez, S. (1995). Materiales para una sociología de la lengua latina. Terencio y los modificadores de imperativo. Florentia Iliberritana. Revista de estudios de Antigüedad Clásica, 6, 347-366.

Penney, J. (2011). Archaic and Old Latin. En Clackson (Ed.), A Companion to the Latin Language (pp. 220-235). Chichester, Reino Unido: Blackwell Publishing Ltd.

Plauto, T. M. (1935). Comédies. (A. Ernout, trad.). Paris: Societé d'Edition les Belles Lettres.

Plauto, T. M. (s. f.) Cistellaria. Recuperado de http:// thelatinlibrary.com/plautus/cistellaria. shtml

Plauto, T. M. (2010). Comedias. (Vol. I y II). J. R. Bravo (Ed.). Madrid: Cátedra.

Plauto, T. M. (2016). Complete Works. Hastings: Delphi Classics.

Quintillà Zanuy, M. T. (2005). Los sexolectos a la caracterización del discurso femenino en el ámbito grecolatino. Faventia, 27(1), 5-62.

Serrano, M. J. (2008). El rol de la variable sexo o género en sociolingüística: ¿diferencia, dominio o interacción? Boletín de Filología, 43, 175 -192. 